\title{
Movement of autonomous systems after selected infrastructure as a globalization effect induced by initiate Industry $\mathbf{4 . 0}$
}

\author{
Josef Botlík $^{1, *}$ \\ ${ }^{1}$ School of Business Administration in Karvina, Univerzitní nám. 1934/3, 73340 Karviná, Czechia
}

\begin{abstract}
The replacement of specialized, highly sophisticated human work with systems using artificial intelligence is one of the features of the 4th Industrial Revolution known as Industry 4.0. The upcoming innovations and transformations of production processes, the digitized of information and the automation will bring about changes at the social level. These are mainly changes in the company's behavior. There is a significant risk for specific groups of people, especially those that can be replaced by new information technologies. In the context of the current sixth wave of globalization, new forms of migration of people and capital can be expected related to transnational nature of productive activities, the global form of communications and information. In the context of socio-economic structures, an individual is confronted with a set of factors. The aim of an individual's behavior is usually to change his localization with respect to the values of the preferred socioeconomic variables, such as availability of work, safety, air quality, etc. On the other hand, the position of an individual will influence the values of socio-economic variables. Behavior can be simulated using multiagent systems. The paper informs about the first phase of the research. Local maxima of factor values were identified.
\end{abstract}

\section{Introduction}

All data tables and figures given in the text are available at www http://pracres.eu/?page_id=385. The reason for this reduction is limiting the scope of the article.

The Fourth Industrial Revolution (Industry 4.0, Work 4.0 etc.) is a designation for the current trend of digitization with related to it automation of production and the labor market changes that it will bring with it. The concept is based on a documentary that was presented at the Hannover fair in 2013. Changes in the labor market are a priority effect, which relates with new controlling, decision-making and robotic systems.

\footnotetext{
*Corresponding author: botlik@opf.slu.cz
} 


\subsection{Industry 4 and labor market}

As a result of automation and IT, routine activities, manual and physically demanding work will be replaced by technology (warehouse workers, cashiers). Some professions can also be expected to disappear.

Compared to previous industrial revolutions can be assumed inequality of impacts on employment, it will be reflected in job losses across working position, both in unskilled work and in highly specialized activities (diagnostic medical systems, legal systems). Significant problems can be expected in the services segment, there is also a definite shift in the level of trade, significant changes can also be expected in warehousing and logistics. Moving between working position ones can be expected, which is conditional on lack of qualification, into the segment outsourcing, Software as a Service etc. According to Deutsche Bank, the fourth industrial revolution will also cover so-called white collars and financial innovations related to the development of cryptocurrencies. The changes will take place continuously in several stages. In the first stage, jobs should decline. It will then increase in the demand for highly qualified workers to take care of the operation of the machines. There is this place for the creation of jobs in information technology (IT), development and marketing communication. Foreign experience shows that 2.5 new jobs should be added per lost job. Low-skilled jobs are likely to be lost, for example in belt production.

It is obvious that the projected impacts vary and evolve over time, while in 2015 the highest potential was seen in the IT sector, in 2016 attention shifted to the service segment and in 2017 to the financial and trade sectors. One of the possible tools for analysis and prediction is simulation using autonomous systems simulating behavior of real population. If we predict the development of jobs, 400,000 jobs will be lost in the Czech Republic, and another one million and a half will undergo, according to the information of Czech Television, fundamental changes. It is predicted that up to $53 \%$ of jobs in the Czech Republic will be lost. This information can be called into question as the changes will be gradual and new jobs will be created. Above all, these will be IT positions. Already today it is possible to trace the requirements in the structure of the production process in areas such as Internet of Things, Artificial Intelligence, Cloud Applications, Big Data, Unified Data Storage, System Engineering, Drawingless Production (Digital Models), Reverse Engineering, Additive Production, (3D printing, etc.), which is closely related to simulation processes and systems engineering. The professional public disagrees on the degree of dominance of IT technologies and the degree of "robotics". The identification of vulnerable groups is problematic because it is not possible to accurately estimate the rate of labor market absorption resulting from the supply of new jobs. However, it is clear that these will be increasingly IT-related positions. Partially it is possible to quantify and identify endangered job positions; these will primarily include positions in the services and robotizable production segment.

\subsection{Current state of knowledge}

The analysis of about 35 documents from 2008-2018 was carried out by Machado et al. [1] with the aim to a systematic review of the links between sustainable manufacturing research and the Industry 4 conceptual framework. The authors point out that the absence of national and regional programs significantly reduces the opportunities offered. In the connection it should be noted, that Ministry of industry and trade elaborated for Czech Republic to Initiative of Industry 4.0 [2] with the aim sustain and strengthen competitiveness of the Czech Republic at the time of the fourth industrial revolution. The initiative was approved by the Czech government on 24 August 2016. Scientific publications examine the effects and impacts of Industry 4 from different angles [3]. There is considerable interest in the so- 
called 4th Industrial Revolution, but this concept is not clear in the literature. Literary research on Industry 4 was also carried out by, for example, Fonseca et al. [4], which aims to present an overview of several industrial revolutions with an emphasis on Industry 4.0. The authors conclude that Industry 4.0 can help organizations reach new and emerging markets through a differentiation strategy or even create new business models. Although according to the authors, this will lead to a significant improvement in job creation, there will also be significant job losses for low-skill employees. Whereas according to the authors, by $201840 \%$ of companies in the European Union still had not adopted any of the new advanced digital technologies, it is necessary to further explore the factors that can accelerate new trends.

Part of the authors analyze possible concrete impacts in terms of technology. Zhang et al. [5], for example, sees the main impacts especially in the production process when targeted robotization occurs. The authors point that the proposed approach can achieve the goal of intelligent production and customized product development. Some authors point out the impacts in terms of the labor market and employment. They point to contradictions where digitization and automation for selected activities can either eliminate the competitive environment, thereby contributing to an increase in the quality of life (increased wages, well-being) or create a threat of unemployment which, together with low incomes, will have negative effects on wellbeing and mental health.

In many cases, there are studies where the stress and threat of job loss caused by automation and digitization induce negative behavior in the workplace, such as Coldwell [6]. The paper is based on secondary data analysis; the theoretical model suggests that extreme forms of behavior associated with the digital era can create organizational entropy. Other approaches to this issue are applied, for example, by Yun et al. [7], focusing on understanding the open innovative micro and macro dynamics for social, environmental, economic and cultural policies and knowledge sustainability. It also provides an overview of the sustainability of the economy, society and the environment during the 4th Industrial Revolution. The author gains the initial knowledge mainly of literature search. Another specific area examined in the context of Industry 4 is the significant social and economic opportunities and challenges that require governments to respond appropriately to support the transformation of society. The aim of the study, which Manda et al. [8] conducted, is identify challenges that developing countries face in adopting digital transformation programs to take advantage of the social and economic benefits of the industrial revolution 4.0. The research is based on an interpretative case study that uses data, third-party documents and literature review as the primary data collection method. The case study focuses on South Africa, the only developing country to adopt digital transformation as its primary growth strategy.

European experience with shaping and regulating socially responsible behavior of economic subjects has Galeska et al. [9], the authors examined the differentiation of dominant driving forces of corporate social responsibility and strategic priorities in Germany in the Industry 4 environment. They identify interconnected types of responsibility (legal, economic, professional, moral, political, etc.) that reflect the system of company values. They draw attention to the deterioration of competition that worsens conditions of economy. They point out the need for modeling based on a strategy of sustainable development, socially responsible behavior of economic structures. The authors also identify the problem of the absence of mechanisms for maintaining social compromise in society. The conclusions of this work clearly show the potential overlap of the impact of Industry 4 on trans-regional ties and the need to investigate the impact of Industry 4 also in the European or transnational context, as the consequences may cause social dissatisfaction leading to economic instability of the region. 
Similar conclusions are provided by Veselica [10], he carries out the description, compares and analyzes the indicators of competitiveness and innovation identifies the relationship between innovation and competitiveness for the national economy in the European context. Severe globalization features and impacts have been identified in particular by Efremov and Vladimir [11]. Especially in IT is education a very important factor in the processes related to Industry 4. Helmi et al. [12] draw attention to the need for transformation in the preparation of experts with contextual knowledge (STEM - Science, Technology, Engineering, Mathematics). Comparative methods are used, for example, by Storolli et al. [13], which performs a comparative analysis of technology tools. It also focuses on environment and sustainable planning.

Comparative methods are also used, for example, by Min et al. [14], which points out the need for transnational and global monitoring of changes induced by the 4th Industrial Revolution, draws attention to the necessity of defining the sites. Some studies [11] use multiple methods of scientific knowledge, analysis, synthesis, generalization, statistical methods based on defining the general principles of construction of the corporate and states social responsibility system and for revealing the nature and apparatus of Industry 4.

From Czech resources, it is necessary to mention Koren [15] who point out that changes in the nature of work, its organization and forms naturally affect the performance of specific types of qualifications and competences, this author also point out possible spatial changes in the labor market. According to the authors [16] of the monograph, the concept of Industry 4 is being misused to camouflage real problems and their causes, to ideologically sterilize political forces and political entities, and to increase the disorientation of people.

Our method is based, for example, on research by Tang and Yi [17], who present a passivity-based analysis using only the local target function, tracking local data and exchanging information from their neighbors. Liang [18] proved suitability of application of multiagent systems to economic processes, the aim was to create a model for analysis of contemporary economic structures. In terms analysis of migration can be found connection with simulations of the process of architecture and development of tourism with help multiagent systems [19]. Other suitable examples of using multi-agent systems and simulation can be found in [20], [21], [22], [23].

\section{Dates and Methods}

\subsection{Basic data}

A group of 29 factors related to Industry 4 were selected for this contribution. The data were examined for the years 2010-2018, 261 data series were analyzed in total. The Eurostat database was used as a primary data base.

The factors are listed in Table 1 (full table with "note" is on pracres.eu). The effect indicates a positive $(+)$ or negative $(-)$ effect on the population. The group indicates what type of indicator it is (edu - education, em - employment, eco - economic factors, $\mathrm{rd}-$ science and development, soc - social). The factors 15-24 relate „Total employment domestic concept", are therefore included in the social group, because they affect the distribution of the population in individual professions and thus can affect the social composition of the population. The negative influence of factors 2,7 etc. is given by the fact that women generally have a less favorable relationship with ICT and robotics. Description and justification of factors is available on the web portal pracres.eu. 
Table 1. Factors used for the analysis

\begin{tabular}{|l|l|l|l|}
\hline in & factor & ef & Gr \\
\hline 1 & Total employment (resident population concept - LFS), total & + & Em \\
\hline 2 & Total employment (LFS), female & - & Em \\
\hline 3 & Gross domestic expenditure on R\&D (GERD) & + & RD \\
\hline 4 & Early leavers from education and training by sex & - & Edu \\
\hline 5 & Early leavers from education and training by sex female & + & Edu \\
\hline 6 & Tertiary educational attainment & + & Edu \\
\hline 7 & Tertiary educational attainment female & - & Edu \\
\hline 8 & Resource productivity & + & Eco \\
\hline 9 & Purchasing power standard (PPS) per kilogram & - & Eco \\
\hline 10 & Index resource productivity & + & Eco \\
\hline 11 & Eco-innovation index & + & RD \\
\hline 12 & People at risk of poverty or social exclusion & - & Soc \\
\hline 13 & People at risk of poverty after social transfer & - & Soc \\
\hline 14 & Severely materially deprived people & - & Soc \\
\hline 15 & Agriculture, forestry and fishing & - & Eco \\
\hline 16 & Industry (except construction) & - & Eco \\
\hline 17 & Construction & - & Eco \\
\hline 18 & Wholesale and retail trade, transport, accomodation and food service activities & - & Eco \\
\hline 19 & Information and communication & + & Eco \\
\hline 20 & Financial and insurance activities & - & Eco \\
\hline 21 & Real estate activities & - & Eco \\
\hline 22 & Professional, scientific and technical activities; administrative and support service & & Eco \\
\hline 23 & Pctivities & - & Eco \\
\hline 24 & Arts, entertainment and recreation; other service activities; & - & Eco \\
\hline 25 & HRST: Persons with tertiary education (ISCED) and/or employed in science and & + & RD \\
\hline 26 & SE: Scientists and engineers & + & RD \\
\hline 27 & HRSTO: Persons employed in science and technology & + & RD \\
\hline 28 & HRSTE: Persons with tertiary educ.tion (ISCED) & + & RD \\
\hline 29 & HRSTC: Persons with tertiary educ. (ISCED) and employed in science and technology & + & RD \\
\hline
\end{tabular}

\subsection{Data modification}

Within the individual factors, the ranking of countries in individual years was determined. In case of conformity, the weight of the country was used, calculated according to the size and population. Subsequently, individual factors for the period and negative and positive factors were summarized. The group of EU countries was adjusted on the basis of available data and extended in the first phase to countries that may have an influence on the European countries in the significance of the selected factors, candidate countries, respectively other countries (Customs Union, Monetary Agreement, Central European Free Trade Area etc.): Bosnia and Herzegovina, Northern Macedonia Serbia, Montenegro, Albania and Turkey. Based on the systemic approach, two neighbourhoods are defined, the first being made up of countries neighboring some of the selected countries (Russia, Ukraine, Belarus), and the second being made up of seas or oceans that may form an indirect border. Based on the available data, countries, where data recovery was less than $30 \%$, were finally excluded (Albania, Bosnia and Herzegovina, Iceland, Liechtenstein, Montenegro). For the remaining countries, in the case of incomplete data in the time series, 
the missing data in the relevant year were interpolated from the previous and the next known year. After data addition, $50 \%$ data recovery was tested, and Serbia and Turkey were excluded from data processing. Norway and North Macedonia (76\%) and Switzerland $(79 \%)$ also had a very small data base too. The missing series were supplemented by extremes $(>\max ,<\min )$ in these countries, according to the positivity of the missing factor. For Russia and Turkey, there was a reduction in significance according to the share of the European continent (decrease in value of area and population in proportion to the Asian and European parts). Due to the generated infrastructure, a group of excluded countries has been analytically (not structurally) added to the neighborhood, the statistical data has been replaced by average incoming country data on the structure in order to ensure the passage of agents in these countries from lower factor to higher. The final infrastructure was generated as a combination of physical boundaries and further by geographic coordinates and identification of nearby states regardless of physical neighborhood. In this case, the links were identified by specifying the number of the nearest states and by allowing or disabling the rewriting of the minimum found. In case of, that $\min (\mathrm{A}->\mathrm{B})=$ min $(B->A)$, where $A$ and $B$ are any pair of states minimum found. In case of, than it is necessary to ensure the coherence of infrastructure it is possible to add a pair of identified edges by triangulation.

Depending on the negativity or positivity of the factor, individual countries were scaled. The scaling was based on the ranking of individual countries according to the value of the relevant factor. It was based on the ranking of individual countries according to the value of the relevant factor. Basic scaling is for individual years, then countries were rated for a given factor and year by order of each year.

The evaluation for individual factors in the interim period is determined by the sum of partial years. There were recorded increases or decreases in the valuation of individual states, based on the established order. Differences in ranking between these states were identified by comparing available of states with existing bind (according to the generated infrastructure). Identification was carried out by passing autonomous agents over the infrastructure in random order of the state. Subsequently, precedence matrices were generated for each factor and year, recording the direction of the increase in the monitored values (ranking of states in the given year and factor). At the present stage of the research, the first precedence was calculated. In the case of, that the precedent of the analyzed state is a nearby state or a sea precedent, this precedence is not counted in the case of the first precedence. For multiple (long) precedencies, the precedence is included in the calculation because it can serve as part of a longer path. If the surrounding state or the sea is the initial node of a longer journey, the node is not taken into account.

\section{Results}

In the first phase is generate an infrastructure for agent movement on a set of selected states. Subsequently, year-on-year changes are identified for individual factors, which are compared on the generated infrastructure. For each country, precedents are recorded for each factor and the number of precedents for each country is determined. It indicates how many states in the neighborhood have a lower value of the given factor. Furthermore, precedents of multiple length are identified, which identify pairs of non-neighboring states with maximum and minimum values of the given factor, among which there is a constant increase in the values of the monitored variable (factor). 


\subsection{Virtual infrastructure}

Modeling infrastructure was generated in the first part of the analyzes. The default structure was created by a physical neighbourhood (boundary). The structure was completed by generating a pair of minimum distances between states. Elimination of pairs of identical identified edges between pairs of states was performed by generating one edge without transcription and adding triangulation. (Figure 1 shows the generation of infrastructure). Blue is the initial fragment that has been generated by generating one edge with forbidden repetition. Green is represented by edges created by adding two minima with the possibility of rewriting. The physical border infrastructure (left side), including links to neighbourhood 1 and neighbourhood 2 (sea and neighboring states), is marked in red. The middle part of the picture shows a detailed view, where the connection between Italy and Bosnia through the Adriatic Sea (Slo - Slovenia, Cro - Croatia, Ser - Serbia, Bos - Bosnia and Herzegovina, Ita - Italia, Alb - Albania, Nor - North Macedonia, Mon - Montenegro / neighborhood 1/, Adr - Adriatic Sea / neighborhood 2 /). In the right part is generated infrastructure for autonomous systems (black). This infrastructure is used for other analysis. In the next phase of the research the values of individual factors were compared and weights were assigned. The analysis was based on factors, groups and effects (see table1). The effect is positive or negative, depending on the effects of Industry 4 (for example, a higher share of the IT industry is a positive factor and a higher share of the service industry is a negative factor). Weights have been assigned so that a higher score means more benefit. Thus, for negative factors, the order is reversed. Therefore, more points mean less risk (threat). The graph in Figure 2 shows that several groups of states can be identified for the selected factors. Greece, Portugal, Norway, Italy, Hungary, Switzerland, Latvia, Estonia, Spain, Cyprus, Lithuania. For all these countries, the total score for negative factors is higher than for positive factors. The group with fewer negative points includes Slovakia, Czechia, Slovenia, Belgium, Germany, the Netherlands, France, Finland, Denmark, Sweden, Ireland, Luxembourg, UK. The groups of states with the lowest threat (most points) are more influenced by positive factors. (Netherlands, France, Finland, Denmark, Sweden, Ireland, Luxembourg, UK). The graph also shows that the countries with the highest difference between negative and positive factors and a higher proportion of negative factors are Greece, Latvia, Estonia and Lithuania, which are countries with generally worse economic potential. A similar ratio is similar for Switzerland.

\subsection{Analysis using Precedence}

The next step of the analysis was to calculate the precedents for individual countries for individual factors. Almost 20,000 first precedents and 355 long precedents for individual states and factors in individual years were identified in the period under review. Table 2 shows the numbers of precedences by factor for all countries under review. The smallest number of short precedents was in the "employment" factor, where it was at a minimum (see Table 2). The exceptions were 2010 and 2011 when the number of precedents was slightly higher (2010 - 74, 2011 - 73). Below the average there was also the factor "Agriculture" (values 12-73) and "material deprivation (values72-74). Above average are the factors "Real estate activities", "Professional, scientific and technical activities; administrative and support service activities ", Public administration, defense, education, human health and social work activities ", Arts, entertainment and recreation; other service activities; "HRST", "HRSTE", "HRSTO", "HRSTC" and "SE" (approx. 76-77 precedence). The factor "employment - women" showed the most short precedencies, where the number of precedents ranged from 80 to 81 . For long precedents, minimum values were recorded in 2013 for the 'Real estate activities' factor (6). Maximum precedence rates were identified in 
2014 for the 'material deprivation' factor (19). Interestingly, the distribution of values is the same as the median for both long and first precedencies.

Short precedencies in the European context must show the same numbers because for each pair of states with detention it has always one higher value of the given factor. The number of precedents then shows the ratio to the surroundings. It is thus evident that employment in the area of the monitored countries shows a higher share in relation to the surrounding area than in neighboring countries. It can also be seen that the factor of "material deprivation" is lower in the countries under review. The increase in long precedence values and their decline in 2013 for "material deprivation" shows the depletion of funds after the crisis. A considerable number of long precedents indicate stabilization in individual countries, with neighboring countries showing little differentiation. On the contrary, the minimum of long precedents in "Real estate activities" indicates an increased number of local extremes, which is caused by an increased differentiation of states in this factor. Table 3 shows an overview of the maximum and average values and the median precedence values by country.

Malta has the first lowest precedents, with Spain (220), Portugal (198) Norway (193) and Cyprus (168) showing the lowest values. The graph in Figure 2 shows that these are mainly countries where the importance of negative factors prevails. Austria (1193), France (1056) and Luxembourg (1015) have the maximum number of first precedents. These countries have the best results, taking into account the geographical aspect, and compare the values of the factors to the immediate surroundings. For long precedencies, Malta, Latvia and Portugal show zero precedents for all factors over the entire reporting period. Luxembourg (71), Switzerland (39) and Ireland (37) have the most long precedents. The chart on the right in Figure 3 shows that these countries make up almost half of the precedents (along with North Macedonia). For Luxembourg and Ireland, the number of long precedents corresponds to the values according to the factors, for Switzerland the number is influenced by the geographical location. Long precedents indicate that there are sequences of factor values around the state with a slightly decreasing value, but with a greater geographical impact. Short precedencies indicate a large number of neighboring states in the immediate vicinity with lower factor values. In other words, a long precedence indicates that it is not an isolated (to a certain distance that is less than the length of the long precedence) maximum. Figure 4 shows the geospatial distribution of the first (left) and long (right) parts. Darker color means higher values. If we compare the development according to the changes in the given time interval, in 2010 and 2018, then we can see that the situation is relatively stable. Table 4 shows the basic statistical values. For the first precedents, Luxembourg (122) has the maximum precedence in 2010, followed by France (119) and Austria (118). In 2018 there was a significant increase in Austria (143, max), with high values in France (118), Luxembourg (105), Germany (103) and the Netherlands (100). In both cases, the peak values are above twice the mean, the median in both years being smaller than the mean.

A comparison of the first precedents of all countries is shown in figure 5 . The relative stability in the order of countries with a large number of first precedents is apparent. There is a significant increase in the number of first precedents in Austria (118 -> 143), indicating an increase in values in the sum of all factors and a marked increase in the country's dominance in the region. This is surprising, especially when compared to standard dominant countries such as France and Germany. The development in the number of long precedences is shown in figure 6. In both years monitored, the value of Luxembourg's maximum is evident ( 8 precedents). In 2018, however, this dominance is no longer so pronounced. It is also evident that the number of states with the longest precedents decreased in 2018 (from 20 to 14). Luxembourg, Romania and Switzerland form a 
significant number of long precedents in both years. As can be seen from figure 6, this share in 2018 is higher than 50 percent of the total number of long precedents.

This means that in 2018 local extremes increased in the vicinity of most countries, which do not allow the creation of long precedents. Thus, the uniform distribution of factor values in space has been reduced and disproportion between countries in a geographically close neighborhood has increased. The graph on figure 7 shows that Austria's first precedence increases equally and gradually (except for 2017), while Luxembourg also declines gradually and evenly. For other countries a steady state is apparent.

The Netherlands returned to their original values after a slight decline, Estonia and Greece have similar developments. A slight increase is shown in Belgium (2010 - 2017) and Poland (growth in 2011 - 13, then stagnation). The long precedence (figure 8) shows a large number in Ireland, where the high precedence rates are in 2011-2017, the boundary years of the interval are lower, so they have not been shown in the figure in figure 6 . North Macedonia also has a high precedence. For long precedencies, the volatility of the values is evident, indicating that even if there is stability in the first precedents, states with high numbers of first precedencies are not always local maxima. The spatial layout is apparent from figure 9. They are depicted progressively from left to right: first precedence 2010, first precedence 2018, long precedence 2010, long precedence 2018. The darker color shows higher numbers of precedence.

The next stage was to compare precedences by individual factors. The sub-factors were further grouped by priority area of influence into RD, Em, Soc, Edu and Eco (see Dates and Methods) and by positivity and negativity of action. Results, table (table 5) and figures (figure 10 to figure 19) are available at www pracres.eu.

\subsection{Compared Precedence and real values}

After the precedence analysis the point order obtained by precedence for individual states was compared with the order determined at fair values. Due to uneven representation of factors in groups of factors, the comparison was made on real and proportionally adjusted data. The data was modified as follows: ProporDate = AllDate $/$ SelectionDate.

Proportional data reflect the weight of the relevant set of factors (ECO, EM, RD, EDU, $\mathrm{SOC})$. In essence, they indicate how many sub-factors are involved in a given group. In large numbers, the group's strength is weakened due to the proportionate approach to the whole. This approach is chosen because the individual factors in the group determine the order that assigns points to each country. In the case of the sum of these points, the sum is greater with a number of factors, which must be regulated. If the individual factors were equally represented in the groups, the proportional values would be the inverse of the total values (only the national order would be reversed). Real values, which are recalculated using point order, show a more even distribution than precedence, as can be seen from the percentage distribution (orange line) in Parete charts. Figure 20 shows the order of states in Parete charts. If we compare real and recalculated values with precedents, we find groups of states with similar characteristics.

There is a group of countries that show high scores for real or recalculated values. Malta, for example, has the highest values in the Em group and the Edo proportional group, but in the precedence analysis it reaches zero values (see figure 9, 11, 15, 17). By comparing individual sub-graphs it is possible to find out that long precedencies correspond more closely with real values, the first precedence with proportional values. In the Eco Group, it can be noted that countries like Romania, Luxembourg or North Macedonia are similarly rated in long precedents and real values. In contrast, Germany, France, Austria or Luxembourg are identifiable in early precedents and proportional values. In the Edu group it is similarly possible to trace connections between Switzerland, Luxembourg or Poland 
(Real, long precedent), but there is no connection between the first precedents and the proportional values. If we compare other groups (Em, RD, Soc) we find that the possible dependencies are rather given by groups of states with similar values (for example, in real $\mathrm{RD}$ states between UK and Greece), when it is easy to confuse or purposefully distort the order. The subject of further investigation is the comparison of measured values.

\section{Conclusion and discussion}

As noted in the literature review, in particular Efremov and Vladimírová [11], they point out that globalization is one of the key processes and a major feature of the development of the world economy and significantly reflects fundamental changes in the economic policies of the world's leading powers. The current phase of globalization is characterized by the eradication of established economic ties, protectionism, trade and customs wars and sanctions with the aim of increasing economic instability and a general slowdown in GDP growth rates in competing regions. The opinion of the impasse of the globalization process and of the advent of globalization of the world economy is increasingly expressed. The authors decided to confirm or refute this view. At the beginning, the dynamics of the globalization level index of the countries of the world was analyzed, reflecting the degree of integration of the country into the global political, economic and socio-cultural space. An analysis of the distribution of the benefits of globalization among countries was then carried out. It has been found that the largest companies are now approaching their FDI because the digital economy allows them to operate globally and to act in foreign markets with virtually physical presence. New technologies are leading to changes in the content of international business transactions and brand new multinational business models are emerging. The authors conclude that there is an apparent slowdown in globalization processes at present. However, it is of a temporary nature and mainly concerns traditional assets, while the transnational flows of new activities caused by the 4th Industrial Revolution are substantially strengthened. It can be assumed that there is a new phase of globalization where the driving force is digital technology, which fundamentally changes the ideas and approaches to placing the productive forces in the world, seriously changes the existing value chains, changes the model and strategy of business development.

Just as there are different opinions in the literature on the positive or negative effects of Industry 4 or on the degree of impact on employment and quality of life, it is not possible to accurately estimate the impact and significance of the factors examined. Employment in industry statistically registered in GEO / NACE_R2 as M N - Professional, scientific and technical activities; administrative and support service activities should show a significant level of threat to Industry 4. However, this group includes not only administrative (ie endangered) groups, but also scientific and professional groups, which in turn would have a positive effect in Industry 4. It is also not possible to reliably identify the importance of the proportion of women from statistical data; it is a known fact that women are less interested in ICT. From this, it could be concluded that an increase in the proportion of women in certain sectors will lead to greater threats and less adaptability to the consequences of Industry 4. However, if, for example, there is an increase in women in a negative identifier related to whether it is a quantitative increase or a share increase. It is obvious to the authors that the enumeration of factors is not complete at this time and the views on the use of individual factors may vary, long-term research and specific measurable impacts of Industry 4 will demonstrate the suitability of the parameters and their true weight in the future The paper presented a method that has the potential given by simplifying the analysis into a binary form of data and allowing more intensive work with larger data volumes.

During the research it has been shown that the density of the generated network can significantly affect the resulting number of precedents and the results can be distorted. This 
is evident, for example, in the total number of first precedents in the UK (e.g. figure 4). However, this distortion is natural because the precedence method takes into account the real geospatial context and the results show the relative isolation of the UK. However, this spatial dependence can also lead to misinterpretation, as demonstrated by the example of Malta, which has no precedence and always includes the last positions in a precedent comparison. However, it is at the top of some groups in comparison to fair values. If we analyzed precedence only, we would not record high real values and misinterpret that they do not exist. However, if we analyze the values with respect to the spatial distribution, then the conclusions of the precedence analysis will be correct, because the relative isolation of Malta overrides the significance of the high value of the relevant factor. In practice, it has again been shown that in any analysis process it is necessary to apply a system approach and it is not possible to generalize individual results using isolated methods.

It can be stated that the relationship between the comparison of fair values and precedence has not been proven. In connection with the analysis of individual factors, it can be stated that more developed countries have better positions for positive factors, but may be endangered by negative impacts, less developed ones have the potential of low risk of negative factors. However, on the basis of these findings, the hypothesis of dependence of individual factors cannot be rejected or confirmed. Although precedence analysis has identified countries in which there are similar numbers of precedences (both positively and negatively), the significance of the chosen generated infrastructure and the consequent connection with the comparison of real values is not yet sufficiently investigated. It is clear that the precedence analysis takes into account the spatial context. At present, the research does not aim to analyze all available factors, the selection of a group of factors may be questioned, based on other research and recommendations the data will be adjusted. Factors were selected to include a broad spectrum and traceable data are traceable.

This paper was supported by the project no. SGS/19/2019, "Application of Customer Relationship Management Systems in Small and Medium-sized Enterprises accepted in 2019“.

\section{References}

1. C. G. Machado, M. P. Winroth, P. Mats, E. H. D. R. da Silva. Sustainable manufacturing in Industry 4.0: an emerging research agenda. International Journal of Production Research. (to be published)

2. Iniciativa Průmysl 4. Available from: https://www.mpo.cz/assets/dokumenty/53723/64358/658713/priloha001.pdf

3. F. Prinz, D. M. Chun, S. H. Ahn. Preface for the Special Issue of Sustainable Manufacturing in 4th Industrial Revolution. International Journal of Precision Engineering and Manufacturing-Green Technology. 5, 11 (2018)

4. L. M. Fonseca. Industry 4.0 and the digital society: concepts, dimensions and envisioned benefits. 12th International Conference on Business Excellence (ICBE). 1, 12 (2018)

5. Z. Zhinan, X. Wang, X. Zhu, et al. Cloud manufacturing paradigm with ubiquitous robotic system for product customization. Robotics and Computer-integrated manufacturing. 60, 11 (2019)

6. D. Coldwell. Negative Influences of the 4th Industrial Revolution on the Workplace: Towards a Theoretical Model of Entropic Citizen Behavior in Toxic Organizations. International Journal of Environmental Research and Public Health. 16, (to be published) 
7. J. J. Yun, Z. Liu. Micro- and Macro-Dynamics of Open Innovation with a QuadrupleHelix model. Sustainability. 11, (to be published)

8. M. I. Manda, D. S. Ben. Responding to the challenges and opportunities in the 4th Industrial revolution in developing countries. 12th International Conference on Theory and Practice of Electronic Governance (ICEGOV). 10 (2019)

9. T. Galetska, N. Topishko, I. Topishko. Corporate Social Activities in Germany: The Experience of Companies Baltic. Journal of Economic studies. 5, 8 (2019)

10. R. Veselica. Linking Innovation and National Competitiveness. 37th International Scientific Conference on Economic and Social Development - Socio-Economic Problems of Sustainable Development 8 (2019)

11. V. S. Efremov, I. G. Vladimirova. Globalization of the World Economy: Features of the Current Stage. 40th International Scientific Conference on Economic and Social Development (ESD). 9 (2019)

12. S. A. Helmi, K. Mohd-Yusof, M. Hisjam. Enhancing the Implementation of Science, Technology, Engineering and Mathematics (STEM) Education in the 21st Century: A Simple and Systematic Guide. 4th International Conference on Industrial, Mechanical, Electrical, and Chemical Engineering (ICIMECE). (to be published)

13. W. G. Storolli, I. K. Makiya, C. F: I. Giocondo. Comparative analyzes of technological tools between Industry 4.0 And Smart Cities approaches: the New Society Ecosystem. Independent Journal of Management \& Production. 10, 24 (2019)

14. Y. K. Min, S. G. Lee, Y. Aoshima. A comparative study on industrial spillover effects among Korea, China, the USA, Germany and Japan. Industrial management \& data systems. 119, 18 (2019)

15. V. Koren. The readiness of the labour market in the Czech Republic for Industry 4.0. International Scientific Conference on The Impact of Industry 4.0 on Job Creation . 13 (2018)

16. R. Valenčík. Čtvrtá průmyslová revoluce, nebo ekonomika produktivních služeb? (Praha, VŠFS, 2019)

17. Y. Tang; P. Yi. Distributed coordination for a class of non-linear multi-agent systems with regulation constraints. IET Control Theory and Applications. 12, 9 (2018)

18. P. Liang, H. Hua, J. Zhou. Analysis of Economic Measurement Model Based on Approach of Social Computing. 7th International Conference on Mechatronics, Computer and Education Informationization (MCEI). 4 (2017)

19. L. Bai. Liming. System of Systems Engineering and Geographical Simulation: Towards a Smart Tourism Industry Information Systém. 15th International Conference on Advanced Communications Technology (ICACT). 4 (2013)

20. T. Yang, X. Yi, J. Wu, et al. A survey of distributed optimization. Annual Reviews in Control. 47, 27 (2019)

21. Z. Deng, S. Liang, W. Yu. Distributed optimal resource allocation of second-order multiagent systems. International Journal of Robust and Nonlinear Control. 28, 14 (2018)

22. D. Valbuena, P. H. Verburg, A. K. Bregt. A method to define a typology for agentbased analysis in regional land-use Research. Agriculture Ecosystems \& Environment. 128, 14 (2018)

23. F. Charnley, D. Tiwari, W. Hutabarat, et al. Simulation to Enable a Data-Driven Circular Economy. Sustainability. 11, (to be published) 